\title{
Влияние температуры формирования на морфологию por-Si, получаемого методом Pd-стимулированного химического травления
}

\author{
(ㄷ Г.О. Силаков ${ }^{1}$, О.В. Воловликова ${ }^{1}$, С.А. Гаврилов ${ }^{1}$, А.В. Железнякова ${ }^{1}$, А.А. Дудин ${ }^{2}$ \\ ${ }^{1}$ Национальный исследовательский университет „МИЭТ“, \\ 124498 Зеленоград, Москва, Россия \\ ${ }^{2}$ Институт нанотехнологий микроэлектроники Российской академии наук, \\ 119991 Москва, Россия \\ E-mail: mr.komrad-13@ya.ru
}

Поступила в Редакцию 5 марта 2020 г.

В окончательной редакции 24 марта 2020 г.

Принята к публикации 24 марта 2020 г.

Изучен процесс Рd-стимулированного травления кремния в растворе, содержащем $\mathrm{HF}$ и $\mathrm{H}_{2} \mathrm{O}_{2}$. Показано влияние на морфологию получаемых слоев таких факторов, как длительность травления и температура раствора. Показано, что в процессе Рd-стимулированного травления наночастицы Pd остаются на стенках и дне пор. Такая структура, как было показано в ранних работах, обладает свойством электроокисления спиртов, что дает основания утверждать: формируемые структуры являются структурами типа структур Шоттки. С помощью диаграммы электрохимического равновесия в системе $\mathrm{Si}-\mathrm{HF}$ (aq.) определена модель $\mathrm{Pd}-$ стимулированного травления. Показано, что происходит полирующее растворение $\mathrm{Si}$ без образования промежуточных продуктов $\left(\mathrm{SiO}_{2}\right)$.

Ключевые слова: пористый кремний, металл-стимулированое травление, МАСЕ, наночастицы палладия.

DOI: $10.21883 /$ FTP.2020.08.49645.9356

\section{1. Введение}

В последние годы существенно возрос интерес исследователей к структурам типа контакта Шоттки, сформированным с помощью осаждения наночастиц (НЧ) благородных металлов внутрь пористого кремния (por-Si) [1-3]. Это связано с возможностью применения таких структур в ряде приложений, в первую очередь в альтернативной энергетике для каталитического окисления этанола (direct ethanol fuel cells) [4,5].

Электроокисление этанола на структуре por-Si/HЧ обусловлено наличием центров активации локальных реакций электроокисления [2]. Центр локального электроокисления - это область контакта por-Si c HЧ благородных металлов, т. е. область с барьером типа контакта Шоттки. Высокая удельная площадь поверхности обеспечивает большую плотность центров активации локальных реакций электроокисления спиртов. На морфологию поверхности por-Si влияют такие параметры процесса, как: длительность травления, состав растворатравителя, температура формирования, плотность тока формирования [3].

В ряде работ описаны методы формирования структур por-Si/HЧ двухступенчатым методом [2,6,7]. Сначала электрохимическим методом формируют пористый слой. Затем из растворов солей благородных металлов осаждают металлические наночастицы на дно пор [2]. Однако такой метод формирования структур por-Si/HЧ требует внешних источников тока. Вследствие этого возникает проблема однородного токоподвода к формируемой поверхности пористого слоя. Кроме того, область формирования пористого слоя ограничена геометрическими размерами используемых электрохимических ячеек. Также в данном методе ограничены возможности групповой обработки пластин $[2,8]$. Альтернативой двухступенчатому формированию является использование металл-стимулированного химического травления (metal assisted chemical etching, МАСЕ) с благородными металлами $(\mathrm{Ag}, \mathrm{Pt}, \mathrm{Pd})$. В этом случае наночастицы металла выступают в роли катода по отношению к кремниевой подложке [9], а также остаются на стенках и дне пор [10]. Таким образом, сокращается число необходимых технологических операций. Данный метод позволяет формировать кремниевые структуры с широким спектром геометрических параметров (нити, мезо- и макропористый кремний) $[6,10,11]$. Сегодня большинство исследователей рассматривает в качестве катализатора для MACE Ag, Pt или Au [12-14]. Значительно меньше работ посвящено Рd-стимулированному травлению. Однако для каталитического окисления этанола лучше всего подходит катализаторы на основе $\mathrm{Pd}$, $\mathrm{Pt}$ или сплава $\mathrm{Pd}-\mathrm{Pt}$ [15]. Поэтому использование $\mathrm{Pd}$ в качестве катализатора при формировании слоев por-Si для электроокисления спиртов является актуальным. В существующих публикациях о МАCЕ описываются две возможные модели протекания реакции [14]. Однако для каждого металла-катализатора модель должна быть установлена отдельно $[16,14]$. Кроме того, нет данных о влиянии параметров процесса MACE c Pd на морфологию получаемого por-Si $[14,17]$.

Таким образом, целью данной работы является исследования Рd-стимулированного травления кремния при различных температурах $\left(25,50,75^{\circ} \mathrm{C}\right)$ и длительностях $(1800,3600,5400,7200$ c) и уточнение модели этого процесса. 


\section{2. Экспериментальная часть}

Пористые слои формировали на поверхности пластин монокристаллического кремния (mono-Si) p-типа проводимости марки КДБ-0.01 (100). Перед формированием образцы отмывали в растворе ПАР, $\mathrm{H}_{2} \mathrm{O}_{2}(30 \%) / \mathrm{NH}_{4} \mathrm{OH}$ (водный, ч.д.а.) $/ \mathrm{H}_{2} \mathrm{O}$, в объемном соотношении $1 / 1 / 3$. Использовали образцы площадью $1 \mathrm{~cm}^{2}$, толщиной $(450 \pm 10)$ мкм. Для удаления естественного оксида образцы погружали в раствор HF (40\%). Наночастицы $\mathrm{Pd}$ осаждали путем погружения образцов в водный раствор $\mathrm{PdCl}_{2}: \mathrm{HCl}\left(0.5\right.$ г/л $\mathrm{PdCl}_{2}$ и 20 мл/л $\left.\mathrm{HCl}\right)$ на 30 мин при $25^{\circ} \mathrm{C}$. Формирование пористых слоев проводили в стандартном растворе для формирования por-Si, $\mathrm{HF}(40 \%): \mathrm{H}_{2} \mathrm{O}_{2}(30 \%): \mathrm{H}_{2} \mathrm{O}$ (25/10/4 по объему), при температурах 25,50 и $75^{\circ} \mathrm{C}$. Длительность травления составляла $30-120$ мин $(1800-7200 \mathrm{c})$.

Измерения пористости и скорости растворения mono-Si проводили гравиметрическим методом. Образцы взвешивали до начала формирования пористого слоя (масса $m_{1}$ ). Затем нерабочую сторону образца полностью покрывали химически стойким лаком (ХСЛ) и сушили на воздухе. После обработки в $\mathrm{HF} / \mathrm{H}_{2} \mathrm{O}_{2} / \mathrm{H}_{2} \mathrm{O}$ образцы промывали в 95\%-м растворе этилового спирта и сушили на воздухе при температуре $60^{\circ} \mathrm{C}$. После сушки химически стойкий лак удаляли и образцы снова взвешивали (масса $m_{2}$ ). Затем пористый слой растворяли в водном растворе $\mathrm{NaOH}(\mathrm{pH}=12)$ и снова взвешивали (масса $\left.m_{3}\right)$. Погрешность измерений $\mathrm{mx}$ составляла \pm 0.00005 г.

Пористость $(P)$ определяли по известной формуле

$$
P=\frac{m_{1}-m_{2}}{m_{1}-m_{3}} \cdot 100 \%,
$$

где $m_{1}$ - масса образца до начала формирования пористого слоя, $m_{2}$ - масса образца после травления, $m_{3}$ - масса образца после удаления пористого слоя.

При известной площади поверхности $S$, которая определялась маской ХСЛ, определяли скорость растворения mono-Si $\left(v_{\text {sol }}\right)$ по известной формуле

$$
v_{\mathrm{sol}}=\frac{m_{1}-m_{2}}{S} .
$$

Преобладающий диаметр пор и толщину пористого слоя определяли с помощью оптической микроскопии с использованием микроскопа Axiovert 40 МАТ (CarlZeiss, Германия) и растровой электронной микроскопии (РЭМ) с использованием установки Helios NanoLab 650 (FEI Company, CША). Полученные изображения обрабатывали с помощью свободно распространяемого программного обеспечения Fiji.

\section{3. Обсуждение результатов}

\section{1. Влияние длительности и температуры формирования на скорость растворения mono-Si}

На основании гравиметрических измерений и статистической обработки данных установлены зависимости скорости растворения топо-Si и численные значения пористости образца от длительности и температуры обработки. Температуру раствора в процессе травления поддерживали постоянной. Результаты представлены в таблице.

Преобладающий радиус пор определяли по такой характеристике на гистограммах распределения пор по размерам, как максимальное число пор данного радиуса $R$, с погрешностью $R \pm 2$ мкм. Толщину пористого слоя определяли по изображениям скола образцов. Результаты представлены на рис. 1 и 2.

Зависимости преобладающего радиуса пор от длительности травления (рис. 1) можно описать полиномом второго порядка. Такая зависимость типична для процесса химического формирования пористых материалов $[18,19]$.

В зависимости толщины пористого слоя от температуры и длительности травления (рис. 2) наблюдаются две характерные области.

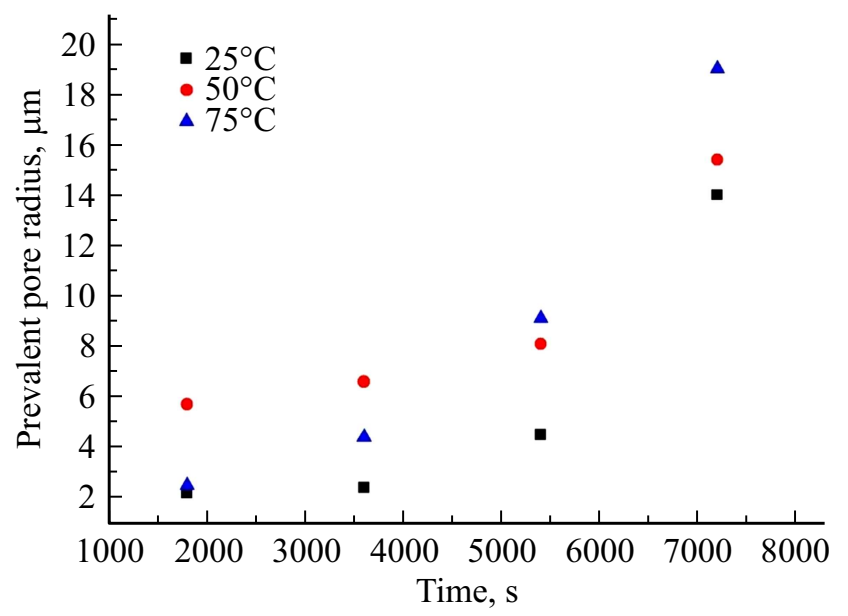

Рис. 1. Зависимости преобладающего радиуса от длительности формирования.

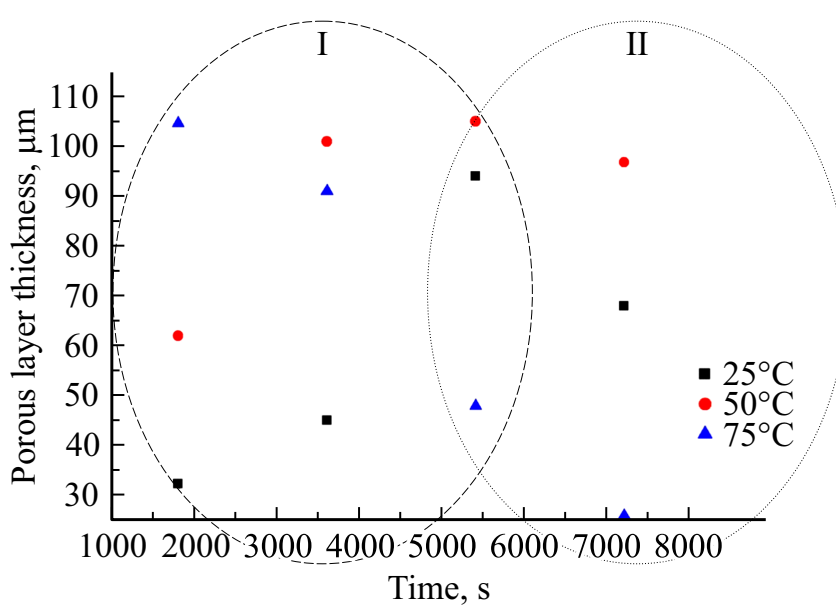

Рис. 2. Зависимости толщины пористого слоя от длительности и температуры формирования. 
Зависимость пористости образцов и скорости растворения mono-Si от длительности формирования для трех различных температур

\begin{tabular}{c|c|c|c}
\hline$T,{ }^{\circ} \mathrm{C}$ & $\begin{array}{c}\text { Длительность } \\
\text { формирования, с }\end{array}$ & $P, \%$ & $v_{\mathrm{sol}}, \Gamma \cdot \mathrm{cm}^{-2} \cdot \mathrm{c}^{-1}$ \\
\hline 25 & 1800 & 31.5 & $3 \cdot 10^{-6}$ \\
& 3600 & 48.6 & \\
& 5400 & 69.1 & \\
\hline \multirow{2}{*}{50} & 7200 & 87.3 & $5 \cdot 10^{-6}$ \\
& 3600 & 48.3 & \\
& 5400 & 79.1 & $20 \cdot 10^{-6}$ \\
& 7200 & 97.7 & \\
\hline 75 & 1800 & 90.5 & \\
& 3600 & По.7 & \\
& 5400 & Полное & \\
& & образцарение & \\
& 7200 & То же &
\end{tabular}

Область I - длительность $1800-5400$ с. Толщина пористого слоя возрастает для температур 25 и $50^{\circ} \mathrm{C}$. Максимальное значение толщины пористого слоя составляет 94 мкм для $T=25^{\circ} \mathrm{C}$ и 105 мкм для $50^{\circ} \mathrm{C}$. Для случая формирования при $T=75^{\circ} \mathrm{C}$, напротив толщина пористого слоя уменьшается. Это можно объяснить ростом скорости растворения как подложки, так и уже сформированного слоя por-Si при повышении температуры.

Область II — длительность от 5400 до 7200 с. В этой области для всех температур толщина слоя por-Si убывает. Это происходит вследствие растворения уже сформированного слоя por-Si c ростом температуры и/или длительности травления [20].

\section{2. Модель Pd-стимулированного травления кремния}

Известны две модели, описывающие процесс металлстимулированного травления кремния [14]. В общем случае процесс металл-стимулированного химического травления описывается следующим уравнением [21]:

$$
\mathrm{Si}+6 \mathrm{HF}+\frac{n}{2} \mathrm{H}_{2} \mathrm{O}_{2} \rightarrow \mathrm{H}_{2} \mathrm{SiF}_{6}+n \mathrm{H}_{2} \mathrm{O}+\frac{4-n}{2} \mathrm{H}_{2} \uparrow,
$$

где $n=2$ для формирования пористого слоя, $n=4$ для электрохимической полировки кремния.

Данное уравнение можно разложить на более простые [21].

Сначала происходит разложение перекиси на металлической частице и диффузия образовавшихся носителей (дырок) в кремний:

$$
\mathrm{H}_{2} \mathrm{O}_{2}+2 \mathrm{H}^{+} \rightarrow 2 \mathrm{H}_{2} \mathrm{O}+2 h^{+} .
$$

Затем возможны две модели растворения кремния. Происходит либо его прямое растворение в 4-валентном состоянии и его переход в $\mathrm{H}_{2} \mathrm{SiF}_{6}$, либо переходу кремния в $\mathrm{H}_{2} \mathrm{SiF}_{6}$ предшествует его окисление до $\mathrm{SiO}_{2}$ и удаление оксида в плавиковой кислоте [21].

1) Прямое растворение кремния в четырехвалентном состоянии:

$$
\begin{gathered}
\mathrm{Si}+4 h^{+}+4 \mathrm{HF} \rightarrow \mathrm{SiF}_{4}+4 \mathrm{H}^{+}, \\
\mathrm{SiF}_{4}+2 \mathrm{HF} \rightarrow \mathrm{H}_{2} \mathrm{SiF}_{6} .
\end{gathered}
$$

2) Окисление кремния с последующим растворением оксида

$$
\begin{gathered}
\mathrm{Si}+2 \mathrm{H}_{x} \mathrm{O}+4 h^{+} \rightarrow \mathrm{SiO}_{2}+4 \mathrm{H}^{+}, \\
\mathrm{SiO}_{2}+6 \mathrm{HF} \rightarrow \mathrm{H}_{2} \mathrm{SiF}_{6}+2 \mathrm{H}_{2} \mathrm{O} .
\end{gathered}
$$

Растворение кремния непосредственно под металлической частицей можно описать уравнением

$$
\mathrm{Si}+4 \mathrm{HF}^{2-} \rightarrow \mathrm{SiF}_{6}^{2-}+2 \mathrm{HF}+\mathrm{H}_{2} \uparrow .
$$

Определить, какая из моделей наиболее точно описывает процесс Рd-стимулированного травления, можно, используя известную диаграмму электрохимического равновесия в системе $\mathrm{Si}-$ (водный раствор $\mathrm{HF}$ ) [22].

Потенциал гальванопары кремний/благородный металл для случая $\mathrm{Si} / \mathrm{Pd}$ составляет $E=0.951$ В [23]. Для раствора $\mathrm{HF} / \mathrm{H}_{2} \mathrm{O}_{2} / \mathrm{H}_{2} \mathrm{O}$ (25/10/4 по объему) $\mathrm{pH}$ можно рассчитать по известной формуле

$$
\begin{gathered}
\mathrm{pH}=-\lg \left[\mathrm{H}^{+}\right], \\
{\left[\mathrm{H}^{+}\right]=\sqrt{K+C},}
\end{gathered}
$$

где $K=6.8 \cdot 10^{-4}-$ константа диссоциации $\mathrm{HF}$, $C=0.036$ моль $\cdot \pi^{-1}-$ концентрация фтористоводородной кислоты в растворе $\mathrm{HF} / \mathrm{H}_{2} \mathrm{O}_{2} / \mathrm{H}_{2} \mathrm{O}$, т. е. для используемого раствора $\mathrm{pH}=0.71$.

Из диаграммы электрохимического равновесия [22] для $E=0.95 \mathrm{~B}$ и $\mathrm{pH}=0.71$ установлено, что формирование пористого слоя происходит по механизму I ((уравнения (5), (6)), т.е. прямое растворение четырехвалентного $\mathrm{Si}$ без образования промежуточных продуктов $\left(\mathrm{SiO}_{2}\right)$. Растворение кремния происходит по механизму полирующего травления непосредственно под металлической наночастицей (макропоры) и фотостимулированного травления по краям поры (мезопористый слой).

Таким образом, процесс металл-стимулированного травления кремния $p$-типа проводимости происходит в 3 этапа [21]:

- разложение перекиси на металле и инжекция носителей (дырок) в кремний;

- формирование цилиндрического канала (макропористый слой);

- травление стенок пор с образованием мезопористого слоя. 


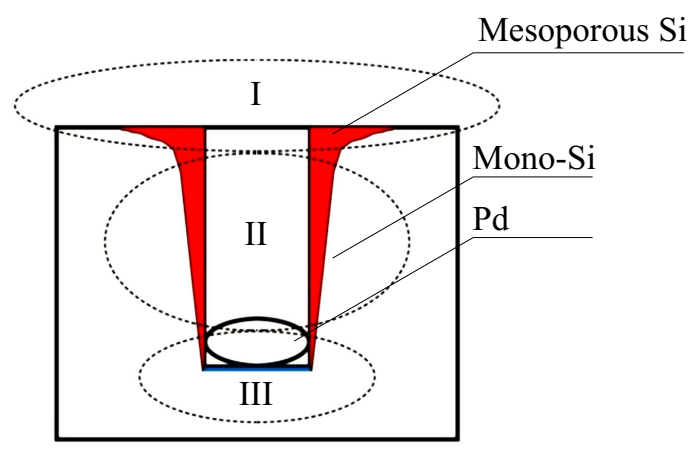

Pис. 3. Три области формируемого пористого слоя: I - вершина поры, область фотоэлектрохимического растворения por-Si; II - область формирования мезопористого слоя; III - дно поры, область протекания реакции МАCЕ.

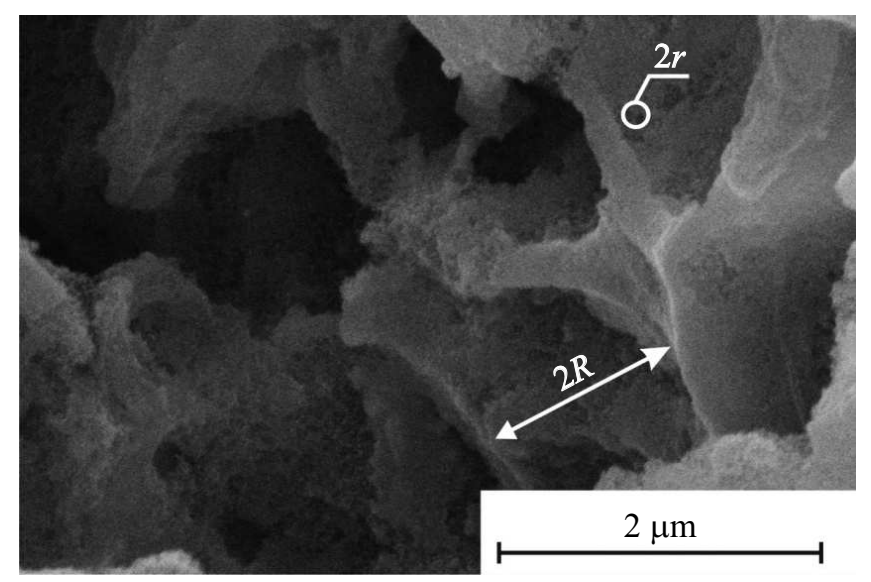

Рис. 4. РЭМ-изображение одной из сформированных макропор, вид сверху, угол наклона $52^{\circ} . R-$ радиус макропоры, $r-$ радиус мезопор на стенках макропоры.

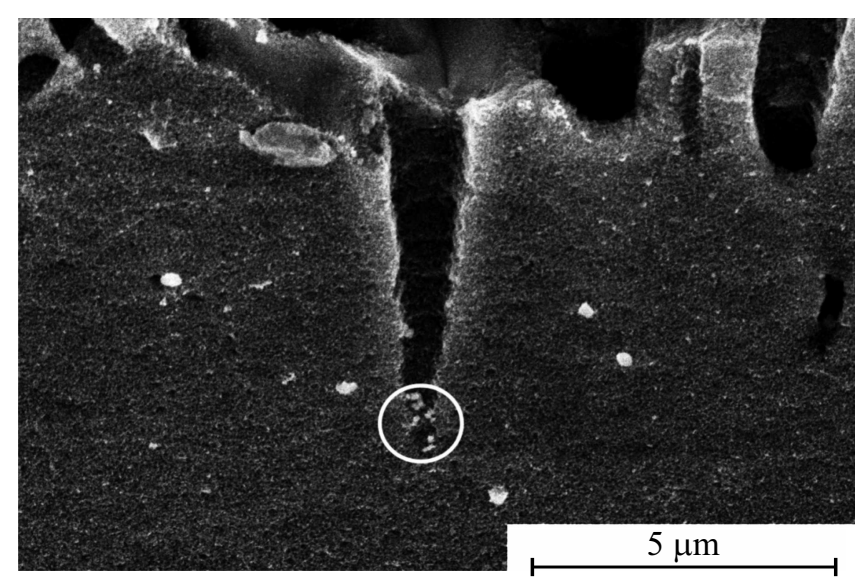

Рис. 5. РЭМ-изображение сформированного слоя. Обводкой показаны наночастицы палладия на дне поры.

Bce 3 этапа могут проходить параллельно.

На первом этапе происходит восстановление перекиси из раствора на металлических частицах, инжекция образованных в результате этого носителей в кремний согласно уравнению (3) и начинается процесс травления.
На втором этапе происходит формирование поры. Концентрации реагентов вблизи дна и вершины поры примерно одинаковы.

Со временем в связи с истощением раствора по $\mathrm{HF}$ и $\mathrm{H}_{2} \mathrm{O}_{2}$ у дна поры (третий этап), концентрация реагентов около металлической частицы уменьшается, соответственно уменьшается и количество носителей, инжектируемых в монокристаллический $\mathrm{Si}[18,23]$. В то же время у верхнего края поры продолжается фотостимулированная генерация носителей [24], и, таким образом, пора растет вширь, образуя слои мезопористого $\mathrm{Si}$ на стенках поры.

На данном этапе пору можно условно разделить на 3 области, как показано на рис. 3 .

В области I происходит растворение сформированного пористого слоя [13]. В области II происходит металлстимулированное травление стенок поры с образованием макропористого слоя. В области III вследствие истощения раствора и высокой поглощающей способности por-Si [25] скорость протекания реакции MACE ниже, чем фотоэлектрохимическое растворение в области I, что подтверждается зависимостями, представленными на рис. 1 и 2, а также РЭМ-изображениями, представленными на рис. 4 и 5. Таким образом, происходит растрав вершины и стенок поры с образованием на них мезопористого слоя.

Результаты анализа РЭМ-изображений (рис. 4) указывают на то, что пористый слой на стенках пор имеет губчатую структуру. Установлено, что преобладающий диаметр мезопор $(r)$ составляет $(50 \pm 10)$ нм. Такой образец будет обладать высокой удельной площадью поверхности. Поскольку наночастицы Pd остаются на стенках и дне поры (рис. 5) и, кроме того, формируемая структура обладает эдс, обеспечиваемой электроокислением этанола [26], то с высокой вероятностью можно утверждать, что формируемая структура является структурой типа контакта Шоттки.

Таким образом, можно утверждать, что в процессе металл-стимулированного химического травления с использованием Pd формируется функциональный слой, представляющий из себя структуры типа контакта Шоттки.

\section{4. Заключение}

В работе исследован процесс Рd-стимулированного химического травления монокристаллического кремния при температурах 25, 50 и $75^{\circ} \mathrm{C}$ и длительностях 1800-3600 с. Показано, что результатом такого травления являются структуры типа контакта Шоттки, состоящие из слоя пористого кремния и наночастиц металла (Pd), которые остаются на стенках и дне пор. Установлен механизм формирования пористого слоя. Он представляет собой полирующее травление топо-Si непосредственно под наночастицами Pd без образования промежуточных продуктов $\left(\mathrm{SiO}_{2}\right)$ и описывается 
следующей системой уравнений:

$$
\begin{gathered}
\mathrm{Si}+4 h^{+}+4 \mathrm{HF} \rightarrow \mathrm{SiF}_{4}+4 \mathrm{H}^{+}, \\
\mathrm{SiF}_{4}+2 \mathrm{HF} \rightarrow \mathrm{H}_{2} \mathrm{SiF}_{6} .
\end{gathered}
$$

\section{Финансирование работы}

Работа выполнена при финансовой поддержке Российского научного фонда (проект № 19-79-00205).

\section{Конфликт интересов}

Авторы заявляют, что у них нет конфликта интересов.

\section{Список литературы}

[1] L. Zhu et al. Sensors Actuators B: Chemical, 227, 515 (2016).

[2] S. Polisski. Abstract of PhD thesis (Bath, University of Bath, 2010).

[3] В. Трегулов. Пористый кремний: технология, свойства, применение (Рязань, 2011).

[4] Е.А. Козлова, В.Н. Пармон. Успехи химии, 86, 870 (2017).

[5] Z. Kang, C. Tsang, N. Wong, Z. Zhang, S. Lee. J. Am. Chem. Soc., 129, 12090 (2007).

[6] Z. Huang, N. Geyer, P. Werner, J. De Boor, U. Gösele. Adv. Mater., 23, 285 (2011).

[7] Y. Chang, X. Su, X. Shi, C. Wang. Acta Chim. Sinica, 65, 2527 (2007).

[8] О. Воловликова, С. Гаврилов, Г. Силаков, А. Железнякова, А. Дудин. Электрохимия, 55, 1452 (2019).

[9] Г. Силаков, О. Пятилова, С. Гаврилов, А. Шулятьев. Тез. докл. 5 Межждунар. науч.-техн. конф. „Технологии микро- и наноэлектроники в микро- и наносистемной технике" (М., Россия, 2016) с. 78.

[10] Ch. Lee, K. Tsujino, Yu. Kanda, Sh. Ikeda, M. Matsumura. J. Mater. Chem., 18, 1015 (2008).

[11] Y. Qu, L. Liao, Yu. Li, H. Zhang, Yu. Huang, X. Duan. Nano Lett., 9, 4539 (2009).

[12] K. Kolasinski. Semicond. Sci. Technol., 61, doi:10.1088/0268-1242/31/1/014002 (2016)

[13] O. Pyatilova, S. Gavrilov, A. Sysa, A. Savitskliy, A. Shuliatyev, A. Dudin, A. Pavlov. Proc. SPIE, 10224, 1022405 (2016).

[14] O. Hildreth, D. Schmidt. Adv. Func. Mater., 24, 3827 (2014).

[15] M. Akhairia, S. Kamarudin. Internat. J. Hydrogen Energy, 41, 4214 (2016).

[16] S. Yae, Y. Morii, N. Fukumuro, H. Matsuda. Nanoscale Res. Lett., 7, doi:10.1186/1556-276X-7-352 (2012)

[17] X. Xia, C. Ashruf, P. French, J. Kelly. Chem. Mater., 12, 1671 (2000).

[18] M. Sadeghpour-Motlagh, K. Mokhtari-Zonouzi, H. Aghajani, M. GhassemiKakroudi. J. Mater. Eng. Perform., 23, 2007 (2014).

[19] N. Mishra, N. Dabra, A. Nautiyal, J. Hudal, G. Varma, N. Pathak, R. Nath. Ferroelectr. Lett., Sect., 42, 75 (2015).

[20] O. Volovlikova, G. Silakov, S. Gavrilov, A. Dudin, G. Diudbin, Y. Shilyaeva. J. Phys.: Conf. Ser., 987, doi:10.1088/1742-6596/987/1/012039 (2018)

[21] N. Geyer, B. Fuhrmann, H. Leipner, P. Werner. ACS Appl. Mater. Interfaces, 5, 4302 (2013).
[22] S. Gavrilov, A. Belogorokhov, L. Belogorokhova. Semiconductor, 36, 98 (2002).

[23] K. Kolasinski. Nanosci. Res. Lett., 9, 432 (2014).

[24] Э. Бучин, А. Проказников. Письма ЖТФ, 23, 80 (1997).

[25] O. Volovlikova et al. J. Phys.: Conf. Ser., 987, 012039 (2018).

[26] O. Volovlikova, G. Silakov, S. Gavrilov, T. Maniecki, A. Dudin. Micromachines, 10, 872 (2019).

Редактор Л.В. Шаронова

\section{Influence of formation temperature on morphology of por-Si, formed by Pd-assisted chemical etching}

\author{
G.O. Silakov' ${ }^{1}$, O.V. Volovlikova ${ }^{1}$, S.A. Gavrilov ${ }^{1}$, \\ A.V. Zheleznyakova ${ }^{1}$, A.A. Dudin ${ }^{2}$ \\ ${ }^{1}$ National Research University \\ of Electronic Technology, \\ Institute of Advanced Materials and Technologies, \\ 124498 Moscow, Zelenograd, Russia \\ ${ }^{2}$ Institute of Nanotechnology of Microelectronics, \\ Russian Academy of Sciences, \\ 119991 Moscow, Russia
}

\begin{abstract}
The process of Pd-assisted chemical etching of silicon in a solution containing $\mathrm{HF}$ and $\mathrm{H}_{2} \mathrm{O}_{2}$ was studied. The influence of such factors as etching time and solution temperature on the morphology of the formed layers was investigated. It is shown that in the process of Pd-assisted etching, Pd nanoparticles remain on the walls and bottom of the pores. Such structures, as was demonstrated in early works, have the property of electro-oxidation of ethanol, which gives grounds to assert that the formed structures are Schottky-type contacts. Using the electrochemical equilibrium diagram in the Si-HF system, a model of Pd-assisted etching was determined. It is shown that the polishing dissolution of $\mathrm{Si}$ occurs without formation of intermediate products $\left(\mathrm{SiO}_{2}\right)$.
\end{abstract}

